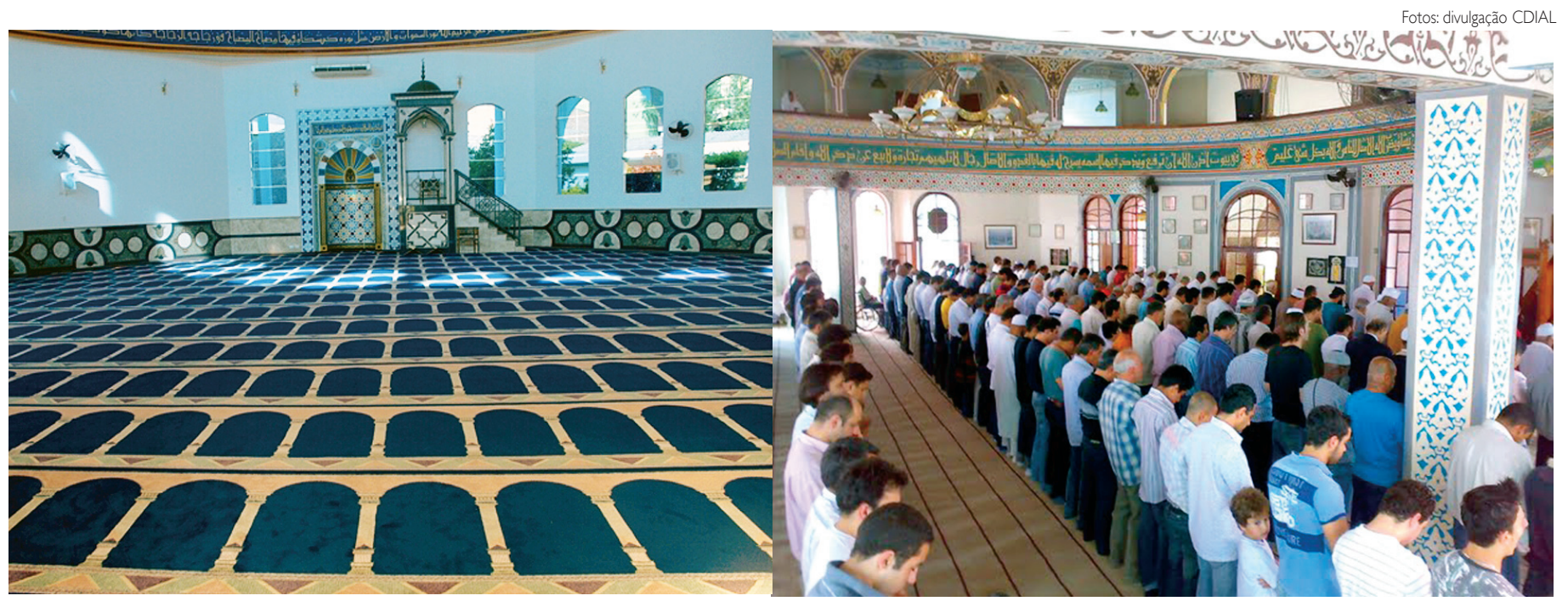

Interior da mesquita em Foz de Iguaçu e uma cerimônia religiosa em Santo Amaro (SP)

\title{
ÁRABES NO BRASIL
}

\section{RIQUEZA CULTURAL E CAPACIDADE DE ADAPTAÇÃO SÃO SUAS MARCAS}

Embora pouca gente saiba, pimenta, noz-moscada, cravo e canela que ressaltam o sabor na culinária brasileira, o uso do azeite no lugar da banha de porco e até o sagrado cafezinho são marcas da cultura árabe, uma influência que vai muito além das esfihas e quibes, totalmente incorporadas em nossa mesa. Os primeiros traços culturais árabes no Brasil chegaram com os portugueses, resultado da influência que absorveram em quase oito séculos de dominação árabe na Península Ibérica. "Junto com os colonizadores, no século XVI, desembarcaram heranças da língua, música, culinária, arquitetura e decoração, técnicas agrícolas e de irrigação, farmacologia e medicina”, escreveu Oswaldo Truzzi, em artigo para a Revista de História da Biblioteca Nacional.

Técnicas de construção como a taipa de pilão, largamente utilizada na arquitetura colonial brasileira, são de influência nitidamente árabe, afirma Truzzi, professor da Universidade Federal de São Carlos. Os arcos em forma de ferradura, cúpulas em forma de gota e os mosaicos de azulejo também são elementos introduzidos por esses povos do Oriente Médio. O cavaquinho brasileiro é um descendente do alaúde, que em árabe significa a madeira. Ritmos árabes estão presentes no côco, dança tradicional do Norte e Nordeste brasileiros, no baião e nos repentes nordestinos, cuja versão árabe é o zajal, também um desafio poético baseado no improviso. "So- mos tributários da cultura árabe desde o início da colonização”, assinala. A partir do século XIX, no entanto, essa influência foi mais direta, marcada pela presença de grande número de imigrantes do Líbano, Síria e Palestina em solo brasileiro. "Os migrantes não eram aventureiros isolados; estavam inseridos num contexto familiar, dispostos a acumular capital durante certo tempo e depois voltar ao seio da família e da aldeia de origem", explica Truzzi. "Entretanto, o que pretendia ser provisório acabou se tornando permanente: em vez do imigrante retornar, em muitos casos foi o restante da família que veio se juntar a ele no Brasil", diz. Entre os fatores que desencadearam a emigração estão o imperialismo europeu, a presença de missionários católicos e protestantes nas regióes árabes do Império Otomano, a crise da indústria da seda na montanha libanesa e os impactos da Primeira Guerra Mundial (1914-1918).

Todos os imigrantes árabes que chegavam ao Brasil eram chamados de 
"turcos". Isso acontecia, em parte, porque os passaportes que usavam, até a Primeira Guerra, eram expedidos pelo Império Otomano. Conforme explica o historiador Paulo Hilu da Rocha Pinto, em 1516 a Síria foi conquistada pela dinastia dos otomanos e fez parte de seu império até 1918. E os otomanos são considerados etnicamente turcos. Outra confusão frequente é pensar que todos os árabes que chegavam (e chegam) ao Brasil são muçulmanos. Rocha Pinto, que coordena o Núcleo de Estudos do Oriente Médio, da Universidade Federal do Rio de Janeiro, lembra que até meados do século XX, a imigração proveniente do Oriente Médio foi predominantemente de cristãos. Apenas 15\% dos imigrantes árabes eram muçulmanos. Outro erro comum é restringir a cultura árabe a homens violentos e mulheres submissas, como se esta fosse a regra entre todos os seguidores do Islã.

PRESENÇA MUÇULMANA Após um período de declínio, a partir dos anos 1970, há uma nova onda migratória de árabes para o Brasil, muçulmana em sua maioria. Os imigrantes deixaram suas nações motivados, sobretudo, pela guerra civil libane$\mathrm{sa}$, pelas guerras árabe-israelenses e pela ocupação israelense dos territórios palestinos e do sul do Líbano. "Com isso, diversas mesquitas foram erguidas em vários estados: Rio de Janeiro, Minas Gerais, Paraná, Mato Grosso, Goiás. A partir de 1990 cresce também o número de brasileiros convertidos ao Islã. "O português passou a ser adotado no sermão das sextas-feiras em comunidades muçulmanas como a do Rio de Janeiro, com grande número de convertidos, ao mesmo tempo em que é crescente a oferta de cursos de língua árabe”, explica o pesquisador. Os muçulmanos demoraram a criar instituições religiosas no Brasil, provavelmente porque preferiram não mobilizar representações estigmatizantes do islã que circulavam na sociedade. A primeira mesquita construída na América Latina, em 1929, fica no Brás, não por acaso, tradicional bairro de comércio popular na capital paulista e um reduto de influência da cultura árabe no Brasil. As práticas religiosas buscavam conciliar a diversidade no interior da comunidade árabe, permitindo que eles construíssem uma moral, pautada pela observância dos costumes e tradições impostos pela religião.

Em seu livro Árabes no Rio de Janeiro: uma identidade plural (2010), Rocha Pinto afirma que o principal signo de identidade expresso pela comunicação ritual das comunidades religiosas que se estabeleceram na cidade era a língua árabe. Ele conta que todas as posições de poder e status dentro da comunidade são ocupadas por fluentes no idioma, demarcando claramente uma hierarquia étnica dentro da comunidade. Existe, inclusive, a preocupação de ensinar a língua aos convertidos e aos descendentes que não conhecem o árabe clássico dos textos religiosos. Há também cursos sobre o Islã. "Eles tendem a focalizar os desafios que as práticas culturais e sociais brasileiras colocam para os muçulmanos, principalmente os convertidos ou os recém-imigrados, tocando questôes como o uso do véu, a proibiçãa do consumo de álcool e da carne de porco e a interação social com amigos e familiares não-muçulmanos", esclarece Rocha Pinto.

A FIGURA DO MASCATE A comunidade árabe é predominantemente urbana. Boa parte dos imigrantes abraçou ocupações do comércio. "Perseguiam a autonomia de gerir seu próprio negócio, ainda que este fosse minúsculo a ponto de caber em uma caixa de vendedor ambulante", conta Truzzi. Além disso, de acordo com Rocha Pinto, eles buscavam atividades que pudessem dar retorno financeiro rápido e transferível para seu país de origem, e a atividade comercial atendia a essas necessidades. "A introdução da barganha e da venda a crédito pelos mascates árabes acabou eliminando a concorrência dos outros grupos étnicos", explica o pesquisador. De acordo com ele, nos anos 1920, muitos ramos do comércio carioca eram dominados pelos árabes. Suas atividades comerciais também tiveram papel importante na integração de áreas rurais e pequenas cidades por causa da procura por novos mercados. "Os mascates procuravam áreas da cidade que não fossem servidas por um comércio estabelecido, como os subúrbios, integrando-os ao mercado urbano. Os recém-chegados tinham de buscar regiōes mais distantes para não enfrentar a concorrência dos mascates já existentes no local e do comércio que se expandia nos subúrbios", diz. No cenário paulista, eles chegaram a ser comparados aos bandeirantes por conta desse papel desbravador.

Patrícia Mariuzzo 